\title{
Intentions vs. efficiency in policy evaluations
}

\author{
Antoine Marie*, \\ Department of political science, Aarhus University, Denmark
}

Hugo Trad

Institut Jean Nicod, Département d'Etudes Cognitives, ENS, EHESS, CNRS, PSL Research University, Paris, France

Brent Strickland

Africa Business School, The School of Collective Intelligence, UM6P. Rabat, Morocco

This manuscript has not been peer-reviewed yet

Please cite as Marie, A., Trad, H., Strickland, B. (2021). Intentions vs. efficiency in policy evaluations. OSF preprint: osf.io/sed $4 \mathrm{w}$

Running Head : Intentions vs. efficiency in policy evaluations

Address for correspondance: Antoine Marie, Department of political science, Aarhus BSS, Aarhus University, Bartholins Allé 7, Aarhus C, Denmark, antoine.marie.sci@gmail.com

\footnotetext{
* Corresponding author: antoine.marie.sci@gmail.com
} 
INTENTIONS VS. EFFICIENCY IN POLICY EVALUATIONS

\begin{abstract}
:
By pragmatic standards, the only thing that should matter is how successful policies are at reaching their objective, relative to their cost. Yet, across 5 online studies $(\mathrm{N}=1515)$, we found that French participants regarded a policy driven by an altruistic intention but that turned out to reach its objective very poorly at a huge cost, as being more commendable than (Experiments 1ad), and as deserving equal support as (Experiment 2), a policy motivated by selfishness but that dramatically helped the issue while saving lots of money. This preference was observed whether the decision was made by a $\mathrm{CEO}$ or minister, and across four issues. Independent manipulation of intent and efficiency (Experiment 2) suggested that folk judgments of policies are characterized both by low sensitivity to huge differences in efficiency (expressed in numerical format), and high sensitivity to actors' intentions. Participants' moral commitment to the issue predicted greater support for any policy version that somehow contributed to help the issue, whatever its level of efficiency and the intention driving it (Experiment 2).
\end{abstract}

\title{
Keywords:
}

Consequences; Efficiency; Intentions; Moral commitment; Moral judgment; Policy 


\section{INTENTIONS VS. EFFICIENCY IN POLICY EVALUATIONS}

Would you prefer a public policy that is highly efficient in taming $\mathrm{CO}_{2}$ emissions but turns out to be motivated by the search for profit, or a policy that fares poorly in curbing emissions but is driven by the good intention to help the environment? Sadly, one may suspect that many people would spontaneously see the former as the most moral of the two options.

In the public and private organizations of democratic societies, electoral processes put vast amounts of executive power in the hands of particular individuals such as ministers and CEOs. This power enables them to make decisions that can massively help society, but also result in considerable wasted money and opportunities when decisions are misguided. From a pragmatic standpoint, what should mostly matter is how successful policies are at concretely reaching their goals - such as curbing $\mathrm{CO}_{2}$ emissions, promoting sex equality in the workplace, or ensuring national defense-relative to the amounts of resources mobilized for their implementation. Assuming the ends pursued by public action enjoy wide public support, citizens' opinions on those policies should not be swayed by whether the actors that put them into effect personally benefitted, electorally or financially.

However, cost-benefit analyses, despite being routine for evidence-based economists and policy makers, do not easily factor into ordinary citizens' judgments about policy, at least in comparison to the weight spontaneously given to actors' motivations. In the domain of charity giving, donors strongly underestimate differences between charities' effectiveness (Caviola et al. 2020), and tend to care less about how much the charities increase human welfare than about whether those charities pursue their preferred causes (Berman et al. 2018). In the domain of folk economic beliefs, the intuition that the "selfish" pursuit of monetary interest on the market is morally bad and incompatible with the common good is widespread, often leading people to reject Adam Smith's notion that private self-regard can make society prosperous and efficient (Boyer \& Petersen 2018; Rubin 2003, 2014).

Likewise, the belief that a technology is driven by the "altruistic" intention to help a social issue seems to contribute much more to its popular support than whether it works at tackling the issue. For instance, despite wide scientific agreement on the safety and usefulness of GMO foods in the fight against world hunger (Wesseler \& Zilberman 2014), part of the resistance they face seems anchored in the intuition that the search for profit driving their industrial development somehow makes them "impure" (of course, other intuitions likely play a role in causing popular 


\section{INTENTIONS VS. EFFICIENCY IN POLICY EVALUATIONS}

distrust towards GMOs, such as naïve essentialist intuitions: Blancke et al. 2015). In a similar way, the prioritization of intent over efficiency may play a role in the public's preference for solar and wind energies over nuclear-despite nuclear being orders of magnitude more productive and reliable than solar and wing for generating electricity (Cameron \& Taylor 2011; Siqueira et al. 2019) — because the former may be perceived as being driven by more disinterested intentions than the latter.

More generally, the intuition that "it's the thought that matters" is central to the moral matrices of WEIRD as well as non-WEIRD societies, and is probably one of the best candidates to the status of moral universal (Henrich, Heine, Norenzayan 2010; Young \& Tsoi, 2013). The centrality of intent is recognized by almost all moral philosophical theories (Walmsley \& O’Madagain 2020), not just deontological (Kant 1785/2005) but also virtue-ethical (Slote 1995) and consequentialist ones (Sidgwick 1884), and is part of a wide class of deontological deviations from consequentialism that comprises intuitions on the importance of fairness, the prohibition to sacrifice, or the preference for harmful omissions over less harmful acts (Baron 1994; Baron \& Spranca 1997; Graham \& Haidt 2012; Haidt 2001, 2012; Tetlock et al., 2000; Tetlock 2003; Spranca, Minsk \& Baron, 1991).

Of course, we do not doubt that giving high moral importance to others' subjective motivations is often quite rational. Whenever others, such as our friends, colleagues and spouses, can physically affect our welfare, ensuring their behavior - as predicted by their values and intentions-will not conflict too much with one's own is obviously adaptive. However, the unequal distribution of power in modern societies creates situations in which, through policy

decisions, huge amounts of social influence can be exerted by particular individuals with whom one will never have any interpersonal relationship. In those circumstances, by pragmatic standards, what should mostly matter is the policies success' and their cost for society, not the nobility of the motivations driving the actors designing them.

\section{Overview of the experiments}

The present paper presents 5 online experiments meant to explore the relative weight of policy makers' intentions and policies' efficiency in folk moral assessments of policies. Experiments $1 \mathrm{a}-\mathrm{c}$ tested whether participants would find an inefficient policy decision driven by 


\section{INTENTIONS VS. EFFICIENCY IN POLICY EVALUATIONS}

an altruistic intention-e.g., a policy intended to protect the environment, but which does so poorly and costs a fortune - as being more morally commendable than a policy decision that is massively efficient but turns out to be motivated by selfishness. We varied which social issue the decision maker's intention altruistically helped vs. selfishly ignored, and whether the decision maker was the $\mathrm{CEO}$ of a private company or a minister.

Experiment 2, by contrast, measured participant's level of support for the policy in nonmoral terms, and focused on the issue of protecting the environment. Its design independently manipulated the policy's efficiency, the intention driving it, as well as the decision maker's identity, in order to parse out their relative contribution to participants' support for policies. Prior research suggests that as people moralize an issue more-i.e., become reluctant to trade it off against other goals - they tend to give more moral weight to actors' intentions to address or on the contrary hinder the issue. In Experiment 2, we therefore looked into how participants' degree of moral commitment to the issue modulated their support for each policy version (Skitka et al 2005; Skitka 2010). We expected greater moral commitment to increase the moral weight given to intentions, thus leading to more praise of altruistically motivated policies (despite potentially low efficiency), and more disapprobation of selfishly motivated policies (despite potentially high efficiency). All experiments in this paper were run on French participants using the software Qualtrics, and recruited on Foule Factory, a French crowdsourcing platform equivalent to Amazon Mechanical Turk.

\section{Experiments 1a-d}

Experiments 1a-d exposed each participant to descriptions of two policies touching on a given issue: curbing CO2 emissions, promoting sex equality in the workplace, promoting France's diplomatic authority in the world, and regulating immigration. On each issue, one policy was described as highly efficient but selfishly motivated, the other as inefficient but altruistically motivated. We also varied the social identity of the decision maker (CEO vs. minister). For believability reasons, on the two issues of protecting the environment using carbon capture technologies and fighting for sex equality in the workplace, the decision maker was a CEO. And 
INTENTIONS VS. EFFICIENCY IN POLICY EVALUATIONS

on the two issues of promoting France's diplomatic authority in the world and regulating immigration, the decision was taken by a minister.

\section{Methods}

\section{Participants}

854 participants were recruited for Experiments $1 \mathrm{a}-\mathrm{d}$. All were paid $€ 0.50$. No respondent was excluded, so the final sample had the following characteristics: $\mathrm{M}_{\text {age }}=43.59 ; \mathrm{SD}_{\text {age }}=13.24 ; 58 \%$ female.

\section{Materials and Procedure}

Experiments 1a-d touched on four distinct issues, manipulated between-subjects: protecting the environment, promoting sex equality in the workplace, promoting France's diplomatic authority in the world, and regulating immigration. Our description of the experimental procedure is based on the two conditions in which the issue was curbing $\mathrm{CO} 2$ emissions, and had a $\mathrm{CEO}$ as decision maker. Small differences between experiments are presented below.

Participants had to give their informed consent to participate. They were randomly presented with two vignettes that narrated the discussion between a decision maker (in this case a CEO) and his advisor on a new policy they were considering to implement. In the Altruistic intent/Low efficiency version of the policy decision, the CEO reported being driven by the altruistic intention to help the issue when considering to launch the policy: "I honestly care deeply about [fighting climate change]." However, his advisor informed him that the policy would cost 100 million euros to the company and that it would only do little to help the issue: "+10\%" impact at the national level and “+0.001\%” impact at the global level.

By contrast, in the Selfish intent/High efficiency version of the policy decision, the decision maker reported being motivated by a selfish reward unrelated to solving the issue: "Honestly, I really don't care about [fighting climate change]. What I care about is [the profits we can make and our company's success.]' However, his advisor notified him that the policy would allow for 100 million euros to be saved by the company, and that it would be highly effective at helping the issue: “+80\%" impact at the national level, and " $+1 \% "$ impact at the global level. 
INTENTIONS VS. EFFICIENCY IN POLICY EVALUATIONS

The Selfish intent/High efficiency policy was thus 8 times more impactful at a national level, and 1000 times more impactful at the global scale, than the Altruistic intent/Low efficiency policy, in addition to being vastly profitable financially as opposed to costing huge amounts of money. Below is the verbatim of the vignettes used:

\section{Altruistic intent/Low efficiency}

The CEO of a global cement and concrete company is considering implementing a new policy: directly capturing $\mathrm{CO}_{2}$ as it is leaving its factories' smokestacks, and then recycle it as an ingredient that makes the factories' concrete stronger.

His chief advisor told him, "If you implement this policy, you will cut our company's $\mathrm{CO}_{2}$ emissions by $10 \%$. But even with our company's size, this would make only a minor difference in the fight against climate change, as it would decrease the world's total $\mathrm{CO}_{2}$ emissions by only $0.001 \%$. This policy would only help the world a little bit."

The CEO responded to the advisor, "I honestly care deeply about deeply about fighting climate change. How much would the policy cost?”

The advisor responded, "By my calculations, our company would loose about 100 million euros with that policy, because the new technology would significantly increase production costs.”

\section{Selfish intent/High efficiency}

The CEO of a global cement and concrete company is considering implementing a new policy: directly capturing $\mathrm{CO}_{2}$ as it is leaving its factories' smokestacks, and then recycle it as an ingredient that makes the factories' concrete stronger.

His chief advisor told him, "If you implement this policy, you will cut our company's $\mathrm{CO}_{2}$ emissions by almost 80\%. Given our company's size, the impact on fighting climate change would be massive, as it would decrease the world's total $\mathrm{CO}_{2}$ emissions by $1 \%$. This is the kind of policy that could really help the world.

The CEO responded to the advisor, "Honestly, I really don't care about fighting climate change. What I care about are the profits we can make and our company's success. How much would the policy cost?"

The advisor responded, "By my calculations, our company would make about 100 million euros with 


\section{INTENTIONS VS. EFFICIENCY IN POLICY EVALUATIONS}

The CEO decided to implement the policy. He indeed reduced his company's $\mathrm{CO}_{2}$ emissions by $10 \%$, thus reducing the world's total net $\mathrm{CO}_{2}$ emissions by $.001 \%$. However, because the CEO cared deeply about his action, he thought it was definitely worth the 100 million euros missed profits. that policy, because the new technology would significantly decrease production costs.”

The CEO decided to implement the policy. $\mathrm{He}$ indeed reduced his company's $\mathrm{CO}_{2}$ emissions by $10 \%$, thus reducing the world's total net $\mathrm{CO}_{2}$ emissions by $.001 \%$. He indeed reduced his company's $\mathrm{CO}_{2}$ emissions by $80 \%$, thus reducing the world's total net $\mathrm{CO}_{2}$ emissions by $1 \%$ and significantly contributing to the fight against climate change. However, more importantly to the $\mathrm{CEO}$, he also made a nice profit of 100 million euros.

Participants were asked to morally assess each one of the two policy decisions by answering the question "To what extent would you say that the [CEO's] decision was commendable?" displayed immediately after each vignette, on the same page. Responses were collected on a 7-point Likert scale (1, "Not at all commendable," 2, "Not commendable," 3, "Somewhat not commendable," 4, "Undecided," 5, "Somewhat commendable," 6, "Clearly commendable," and 7, "Totally commendable").

Participants then reported their level of moral commitment to the issue at stake by answering the question "To what extent do you think that [protecting the environment] should be the government's priority?". Reponses were collected on a slider scale ranging from 0 , "I don't care" to 100 , "Absolute priority," with 50 (no text) as default slider position. The questionnaire ended with demographic questions: political orientation on a 1-item left-right axis, sex, age, level of education.

Differences between Experiments 1a-d. On the issues of environmental protection and the pursuit of sex equality, we chose the $\mathrm{CEO}$ of a private company as decision maker because those were policy interventions that one can easily represent as being implemented at the level of a private company. By contrast, we saw it as more believable that decisions meant to further the homeland 
issues of national authority and immigration regulation be taken at the governmental level, hence a minister as decision maker. Varying the decision maker's identity implied adapting the selfish reward in the Selfish intent/High efficiency decision. It also required adapting which entity would loose vs. gain the 100 million euros as a consequence of the policy. When the decision maker was a CEO, their selfish reward was financial ("What I care about is the profits we can make and our company's success."), and the policy was described as being costly, or beneficial, to their company. By contrast, when the decision maker was a minister, the selfish reward was electoral ("What I care about is to save public money so as to increase chances that our party wins the next elections."), and the policy was described as being costly, or beneficial, to the state.

\section{Results}

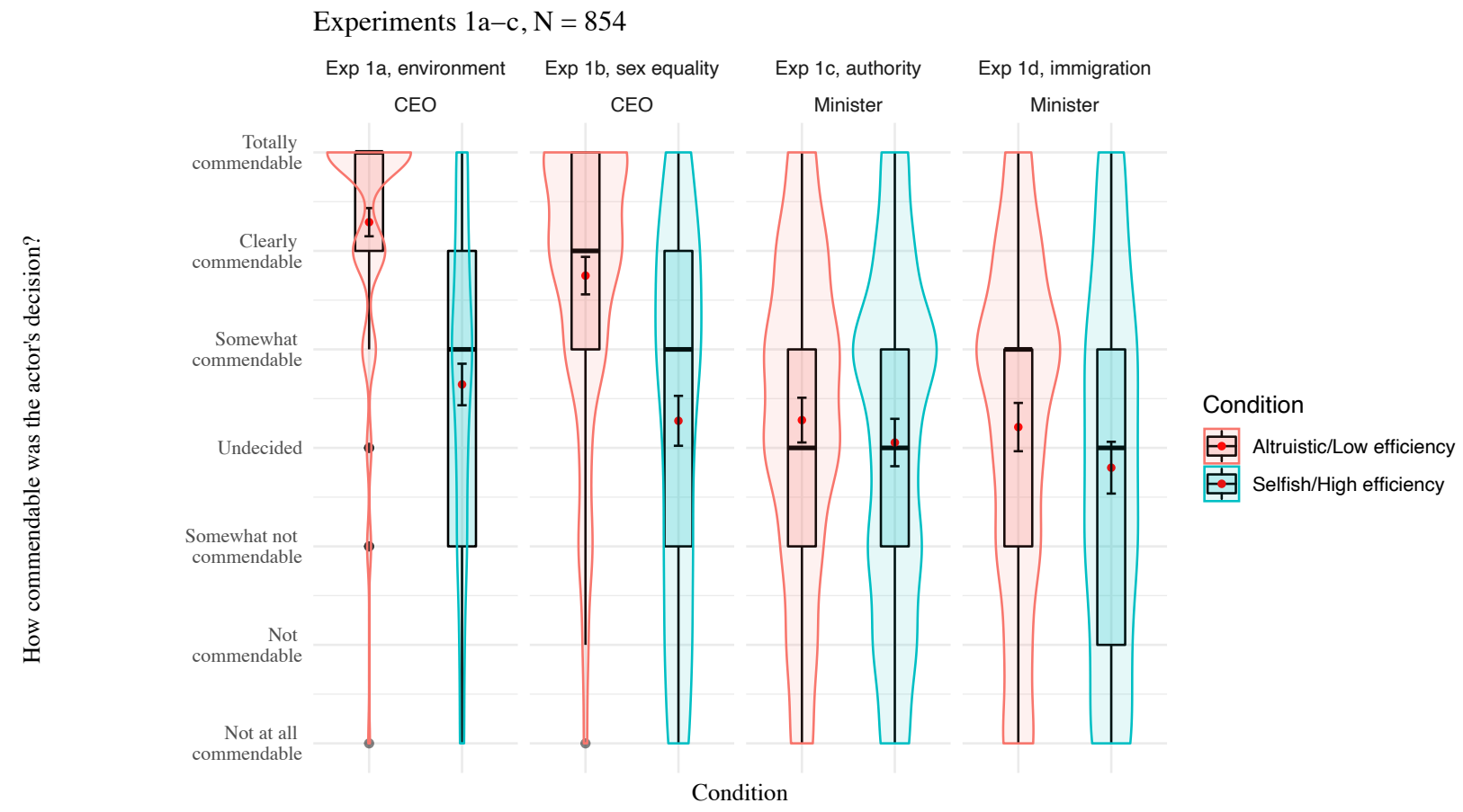

Figure 1: Commendability judgments of policy decisions as a function of decision type and issue in Experiments 1a-d. Black lines are medians, red dots means, and black whiskers are 95\% CIs of the mean. 
INTENTIONS VS. EFFICIENCY IN POLICY EVALUATIONS

All analyses in this paper were run in $\mathrm{R}$ (version 3.6.2) using $\mathrm{R}$ Studio (Version 1.2.5033).

Effect of decision type on judgments. Judgments of commendability of the policy decision were regressed in two linear models on decision type, issue, and moral commitment (see "main models" in Electronic Supplementary Materials after the References section). Main effects are reported from the first model containing the main effects only (decision type, issue, moral commitment), and two-way interactions are reported from the second model containing both the main effects and their two-way interactions. We report regression coefficients, 95\% CIs between brackets, and $p$ s from these models.

Commendability ratings were highest regardless of decision type on the issue of environmental protection, followed by sex equality (main effect of issue: $\beta=-0.17,[-0.29,-0.05], p<0.001$ ), promoting France's authority $(\beta=-0.52,[-0.65,-0.39], \mathrm{p}<0.001)$, and regulating immigration $(ß=-0.63,[-0.76,-0.50], \mathrm{p}<0.001)$. In analyzing across all issues, commendability judgments were significantly lower in the Selfish intent/High efficiency condition than in the Altruistic intent/Low efficiency condition (main effect of decision type: $ß=-0.54,[-0.62,-0.46], p<0.001$ ). We recognized that our within-subjects design could have incentivized participants to exaggerate the difference between their two judgments compared to a between-subjects design. Yet, the Selfish intent/High efficiency decision was still rated as being less commendable than the Altruistic intent/Low efficiency decision when subsetting the data to the first condition participants had been exposed to only (main effect of decision type: $\beta=-0,56,[-0.67,-0.44]$, $\mathrm{p}<0.001)$.

Moreover, the difference between judgments of commendability in the Altruistic intent/Low efficiency and in the Selfish intent/High efficiency decision was smaller on the issues of France's authority (interaction between decision type and issue: $\beta=0.77,[0.54,1.00], \mathrm{p}<0.001$ ) and regulating immigration $(~(=0.67,[0.44,0.90], \mathrm{p}<0.001)-$ two issues on which the decision maker was a minister rather than a CEO (See Figures 1-2 below). 


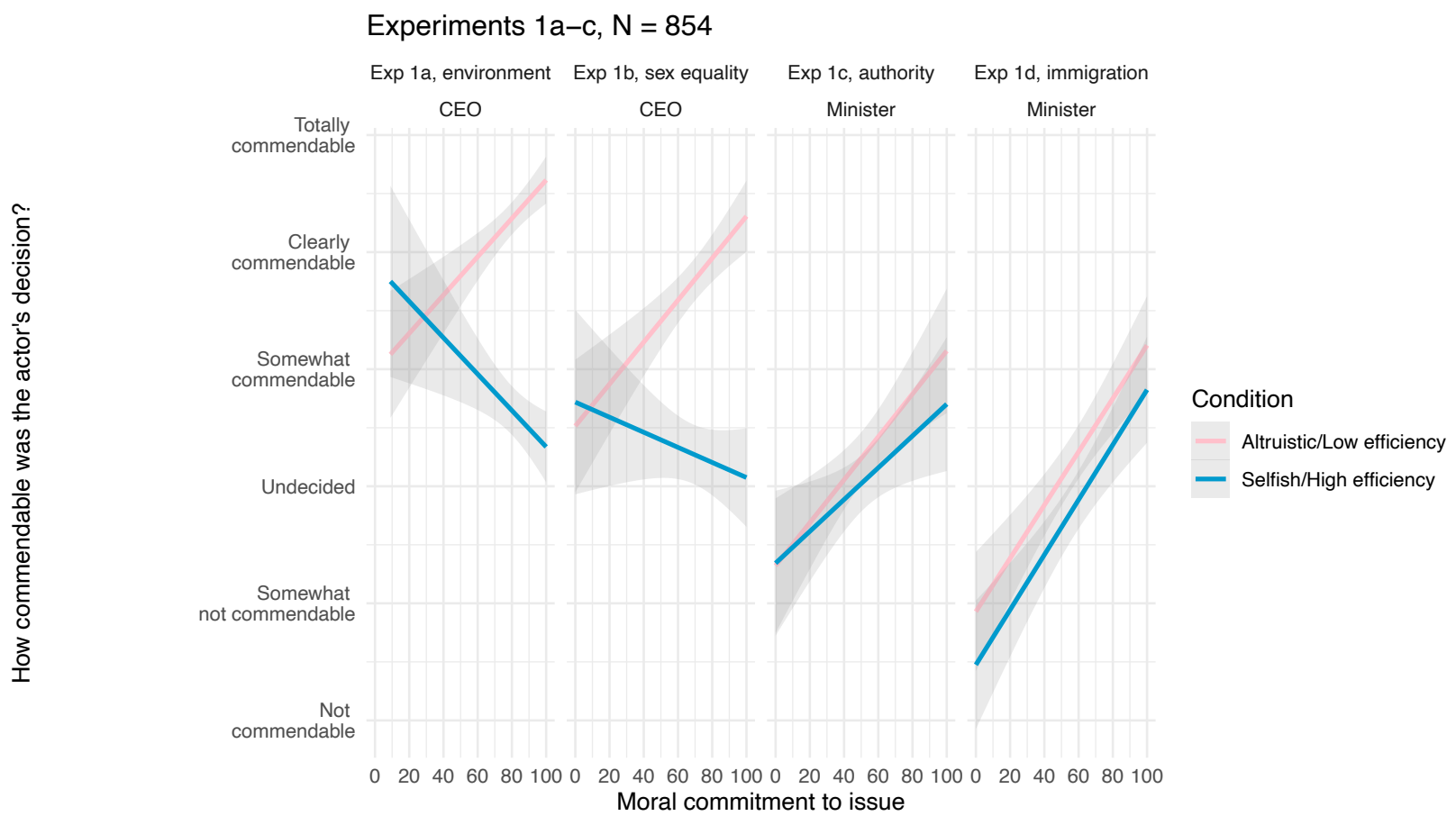

Figure 2: Commendability judgments of policy decisions as a function of moral commitment to the issue, decision type, and issue in Experiments 1a-d. Black lines are medians, red dots means, and black whiskers are 95\% CIs of the mean.

Effect of moral commitment on judgments. Participants reported average levels of moral commitment that were highest on the issue of environmental protection $(\mathrm{M}=80.2$, Median = $82, \mathrm{SD}=18.8)$, followed by sex equality $(\mathrm{M}=68.9$, Median $=71, \mathrm{SD}=23.4)$, France's authority $(\mathrm{M}=56.4$, Median $=60, \mathrm{SD}=28.3)$ and immigration $(\mathrm{M}=52.4$, Median $=54.5, \mathrm{SD}=21.8)$. For ease of interpretation, the effect of moral commitment to each issue on commendability judgments on each issue was assessed using simple linear regressions on each experimental condition (see SM). On all four issues, greater moral commitment to the issue was associated with more praise of the Altruistic intent/Low efficiency decision: Environmental protection: $\beta=$ $0.27,[0.15,0.39], p<.001$; sex equality: $\beta=0.30,[0.17,0.43], p<.001$; France's authority: $\beta=$ 0.24, [0.11,0.38], $\mathrm{p}<.001$; regulating immigration: $ß=0.37,[0.24,0.50], \mathrm{p}<.001$ (see SM). By contrast, greater moral commitment to the issue had contrasted influences on commendability judgments of the Selfish intent/High efficiency decision. It was negative when the decision maker was a CEO: on issues of environmental protection $(\beta=-0.17,[-0.30,-0.05], p<0.01)$ and negative but non-significant on promoting sex equality $(\beta=-0.08,[-0.22,0.06], p=0.24)$. 
INTENTIONS VS. EFFICIENCY IN POLICY EVALUATIONS

However, the effect of moral commitment to the issue was positive when the decision maker was a minister, i.e., on issues of France's authority $(ß=0.17,[0.03,0.31], p<0.01)$ and regulating immigration $(ß=0.36,[0.23,0.49], \mathrm{p}<0.001)$.

\section{Discussion}

Experiments 1a-d found that a policy decision that only helped a key societal issue a little bit at a huge cost, but which was altruistically motivated, was judged as more commendable than a decision at least 8 times more impactful, and financially profitable, but which was selfishly motivated. This result generalized across four distinct issues_-protecting the environment, fighting for sex equality, promoting France's authority in the world, and regulating immigration. It was observed whether the decision maker was a CEO or a minister. We also consistently found that the more participants were morally committed to an issue, the more praiseworthy they saw an altruistically motivated policy despite its poor efficiency.

Since Experiments 1a-d did not independently manipulate issue and decision maker identity, it is unclear why the Altruistic intent/Low efficiency policy decision was rated higher on the issues of environmental protection and sex equality than on France's authority and immigration regulation. This may be due to people expecting greater exertions for the common good from ministers than from CEOs, because the former are state servants while the latter are typically seen as working for private interests only (Rubin, 2014). This assumption may have caused people to deem ministers as deserving less praise less than CEOs for the same altruistic decision. A second and complementary explanation is that participants were on average more morally committed to the former two issues than to the latter two, and that this drove up ratings of the Altruistic intent/Low efficiency policy.

\section{Experiment 2}

The design employed thus far showed that a combination of good intent but low efficiency tended to be seen as more commendable than a combination of bad intent but high efficiency. 


\section{INTENTIONS VS. EFFICIENCY IN POLICY EVALUATIONS}

While those results unambiguously show that laypeople's judgments of policy decisions deviate from pragmatism, the extent to which they are due to insensitivity to differences in efficiency or to intentions being given considerable importance is unclear.

Answering this question requires independently manipulating intent and efficiency, and examining whether judgments track differences in efficiency in the absence of any intentionrelevant information. To do this, Experiment 2, which focused on the issue of protecting the environment, adopted a full factorial design to examine how support for a low vs. high efficiency policy decision without intention specified would be affected by introducing cues to the decision maker's altruistic vs. selfish intention. We meant the "no intention" baseline to gauge how pragmatic participants would spontaneously be in the absence of any cue to the decision maker's motivations. We expected to reproduce our finding that an altruistic but low efficiency decision would be approved of more than a selfish but high efficiency decision. Experiment 2 also varied the decision maker's identity (CEO vs. minister). Finally, we investigated the effect of moral commitment on each version of the policy decision.

\section{Method}

\section{Participants}

661 French participants were recruited on Foule Factory for Experiment 2 in exchange for $€ 0.30$. No participant was excluded from the data $\left(\mathrm{M}_{\text {age }}=39.14 ; \mathrm{SD}_{\text {age }}=12.44 ; 48 \%\right.$ female. $)$.

\section{Materials and procedure}

Experiment 2 focused on the issue of protecting the environment only. The vignettes and procedure were the same as in Experiments 1a-d except for the following changes. Instead of comparing two decision types only, we independently varied the decision maker's intention across three levels (no intention specified, altruistic intent, and selfish intent), the policy's efficiency across two levels (low vs. high), and the decision maker's identity across two levels (CEO vs. Minister). The design was now a 3x2x2 design with 12 conditions, between-subjects in order to avoid that repeated measures artificially inflate differences in judgments. 


\section{INTENTIONS VS. EFFICIENCY IN POLICY EVALUATIONS}

Altruistic and selfish intentions reported by the decision maker were the same as in Experiments 1 , and we suppressed the sentences providing information on the decision maker's intentions in the two relevant paragraphs of the vignettes in the no intention specified conditions. The selfish motivation of the decision maker where slightly changed to "improving the company's image" when they were a CEO, and to "improving the [minister's] political party's image in order to increase chances of winning the presidential elections" when they were a minister.

We also increased the contrast between the low and high levels of the efficiency factor compared to Experiments 1 in order to make it more salient. In the low efficiency conditions, the policy was described as reducing carbon emissions by only $2 \%$ at the national level (instead of $10 \%$ in Experiments $1 \mathrm{a}-\mathrm{d}$ ) and $0.001 \%$ at the global level, and as costing 100 million euros in the long run (to the state when it was a minister vs. to the company when it was a CEO). By contrast, in the high efficiency conditions, the policy was described as contributing $80 \%$ reduction of $\mathrm{CO}_{2}$ emissions at the national level and 10\% reduction at a global scale (instead of 1\% in Experiments 1a-d), and as allowing 100 million euros to be saved in the long run. The high efficiency policy was thus 40 times more impactful at a national level, and 10000 times more impactful at the global scale, than the low efficiency policy, in addition to being vastly financially profitable as opposed to costing a lot of money.

We realized that the dependent variable used in Experiments 1a-d ("To what extent would you say that the [e.g. CEO's] decision was commendable?") could implicitly invite participants to focus on the moral character of the actor's decision to the detriment of the policy's efficiency. This could artificially increase chances their responses deviate from pragmatically paying attention to policy impact. We therefore adopted a more neutral formulation: "To what extent do you support this policy?" with responses collected on a 7-point scale (1, "Not at all," 2, "Clearly not," 3, “Somewhat not," 4, "Undecided," 5, “Somewhat," 6, "Clearly," 7, “Totally”).

Participants then reported their level of moral commitment to environmental protection on a 3item scale: "Protecting nature is an absolute moral imperative," "The conviction that one must fight to protect the environment is central to my identity" (inspired from Skitka et al. 2005; Stahl, Zaal, Skitka, 2016); "Protecting the environment should be the government's priority." Responses were 
collected on 0-100 slider scales anchored in 0, "Totally disagree," and 100, "Totally agree," with 50, "I don't know" as default position. The experiment ended with demographic questions: political orientation, sex, age, and education.

\section{Results}

Experiment 5

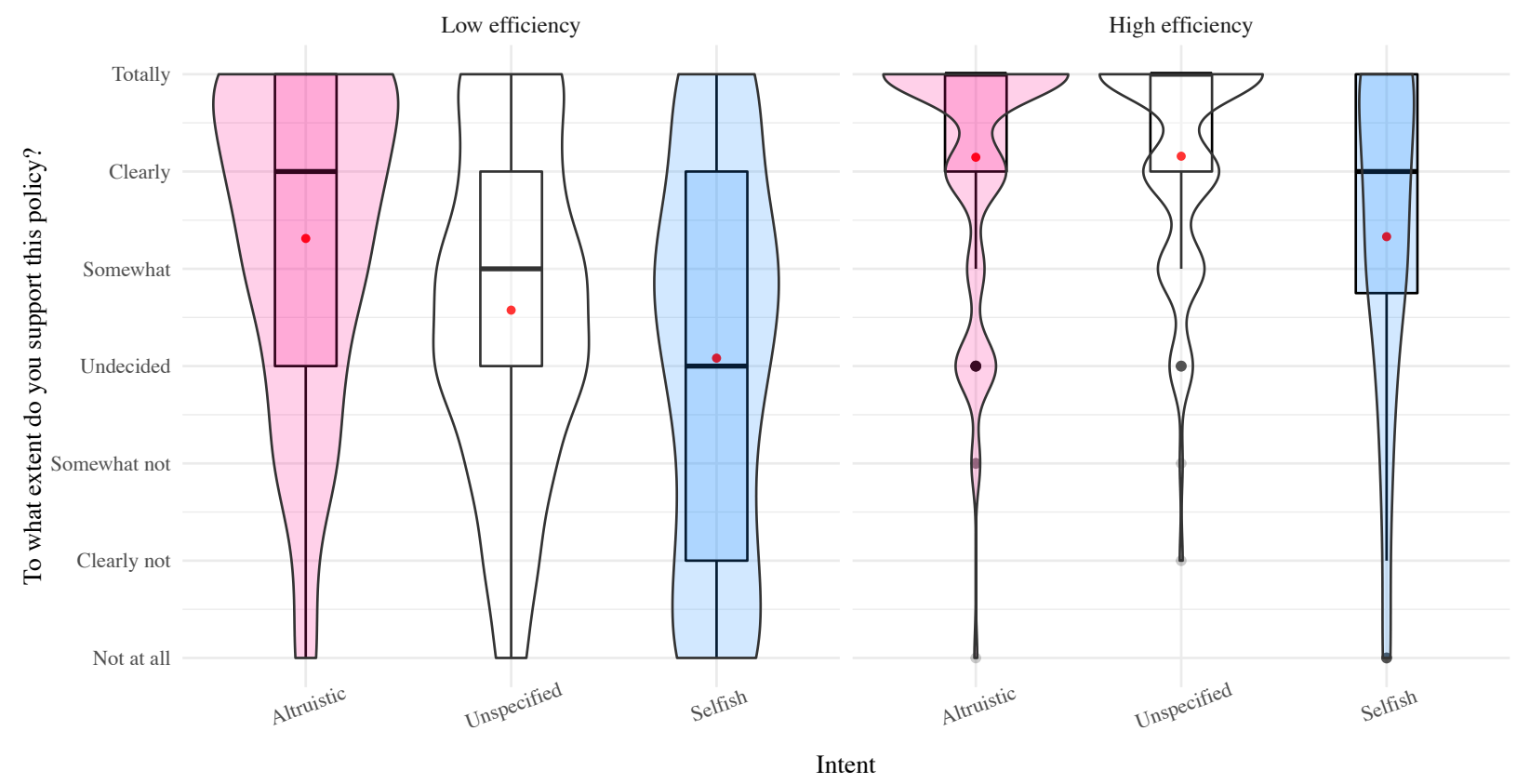

Figure 3: $N=661$. Support for policy judgments in Experiment 2 as a function of intent and efficiency (regardless of decision maker identity). Black lines are medians and red dots means. 


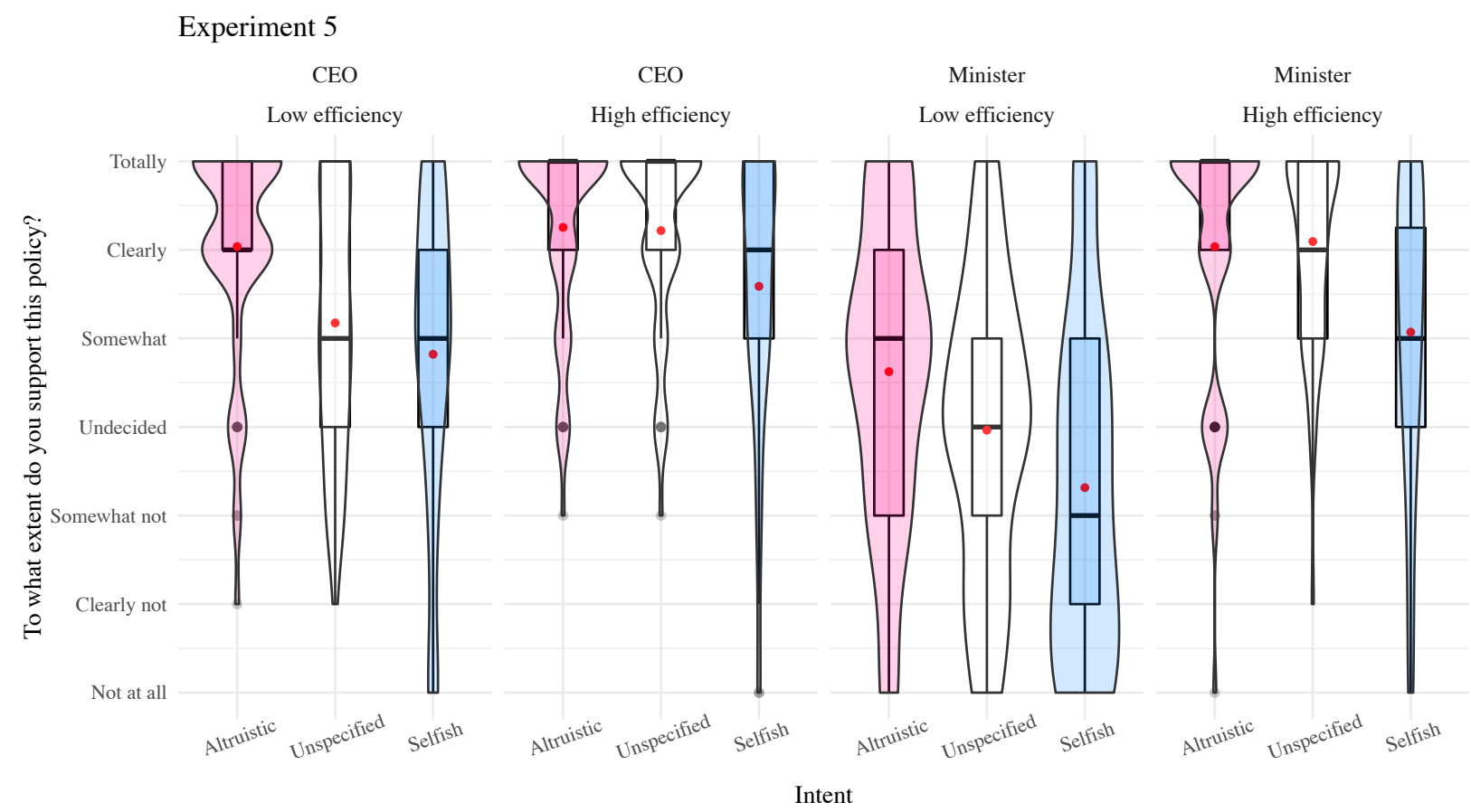

Figure 4: $\mathrm{N}=661$. Support for policy judgments in Experiment 2 as a function of intent and efficiency, breaking down by decision maker identity. Black lines are medians, red dots means.

Effect of efficiency, intent and decision maker identity on judgments. Results were analyzed using two multiple regression models of support for policy judgments on policy efficiency (low vs. high), decision maker intent (unspecified vs. altruistic vs. selfish) and decision maker identity (CEO vs. minister) (see "main models" in SM). Levels listed first in parentheses were set as baselines for each factor in the regression. Main effects are reported from a first model containing only the main effects, and the two-way interactions between those factors are reported from a second model containing both the main effects and the two-way interactions. Welch's t-tests and Cohen's ds were also performed as post hoc analyses; all are non-paired.

The high efficiency policies $(M=5.87$, Median $=6, S D=1.42)$ garnered more support than the low efficiency policies $(\mathrm{M}=4.65$, Median $=5, \mathrm{SD}=1.85)$, regardless of intention and decision maker identity (main effect of efficiency: $ß=0.66,[0.53,0.79]$, $p<0.001$ ). This difference was greater when the decision maker was a minister than a $\mathrm{CEO}$ (interaction between efficiency and decision maker identity: $\beta=0.61,[0.36,0.86], \mathrm{p}<0.001)$, an effect driven mainly by low efficiency policies being supported less when a minister was implementing them $(M=3.98$, Median=4, 
INTENTIONS VS. EFFICIENCY IN POLICY EVALUATIONS

$\mathrm{SD}=1.85)$ than when it was a $\mathrm{CEO}(\mathrm{M}=5.33, \mathrm{Median}=6, \mathrm{SD}=1.58), \mathrm{t}(322)=7.17, \mathrm{p}<0.001$, $\mathrm{d}=0.7$. Focusing on the data corresponding to conditions that did not ascribe any intention to the decision maker, high efficiency policies $(\mathrm{M}=6.16$, Median $=7, \mathrm{SD}=1.09)$ were more supported than low efficiency policies $(\mathrm{M}=4.58, \mathrm{Median}=5, \mathrm{SD}=1.67), \mathrm{t}(193)=-8.37, \mathrm{p}<0.001, \mathrm{~d}=1.12)$. Although this latter effect was, statistically speaking, clearly significant, it is striking that participants' judgments showed so little responsiveness to such huge differences in efficiency described as described by the vignettes. While support for high efficiency policies was around "Clearly", support for the low efficiency policies dropped by only 1,5 scale points to "UndecidedSomewhat," despite the latter having a gigantic cost and tiny impact.

Attributing a selfish motivation to the decision maker decreased support for the decision compared to when no intention was specified (main effect of selfish intent: $\beta=-0.47,[-0.62,-$ 0.31], $\mathrm{p}<0.001$ ), both on low and high efficiency policies. By contrast, ascribing an altruistic intent to the decision maker increased support for the decision (main effect of altruistic intent: $ß=0.17,[0.01,0.33], \mathrm{p}<0.05)$, except on high efficiency policies, presumably because of a ceiling effect on judgments of support (interaction between efficiency and altruistic intent: $ß=-0.39$, $[-$ $0.70,-0.08], \mathrm{p}<0.01)$.

In line with results from Experiments 1, participants in Experiment 2 supported the Altruistic intent/Low efficiency policies at least to the same extent $(\mathrm{M}=5.31$, Median $=6, \mathrm{SD}=1.66)$ as the Selfish intent/High efficiency policies $(M=5.33$, Median $=6, \mathrm{SD}=1.67), \mathrm{t}(218)=-0.08, \mathrm{p}$ $=0.93$. Breaking down by decision maker identity, support for the Altruistic intent/Low efficiency policy was slightly higher $(\mathrm{M}=6.04$, Median $=6, \mathrm{SD}=1.24)$ than for the Selfish intent/High efficiency policy $(\mathrm{M}=5.6$, Median $=6, \mathrm{SD}=1.56)$ when a $\mathrm{CEO}$ was implementing the policy, but the difference was not significant: $\mathrm{t}(103)=1.67, \mathrm{p}=0.1$. When a minister was making the decision, support for the Altruistic intent/Low efficiency policy $(\mathrm{M}=4.62$, Median $=$ $5, \mathrm{SD}=1.72)$ was slightly lower than for the Selfish intent/High efficiency policy $(\mathrm{M}=5.07$, Median $=5, \mathrm{SD}=1.75)$, but the difference was not significant: $\mathrm{t}(109)=-1.36, \mathrm{p}=0.18$. 
INTENTIONS VS. EFFICIENCY IN POLICY EVALUATIONS

There also was a main effect of decision maker identity, such that policies implemented by a minister garnered less support across the board than those made by a CEO ( $B=-0.48,[-0.61,-$ 0.35], $\mathrm{p}<0.001)$.

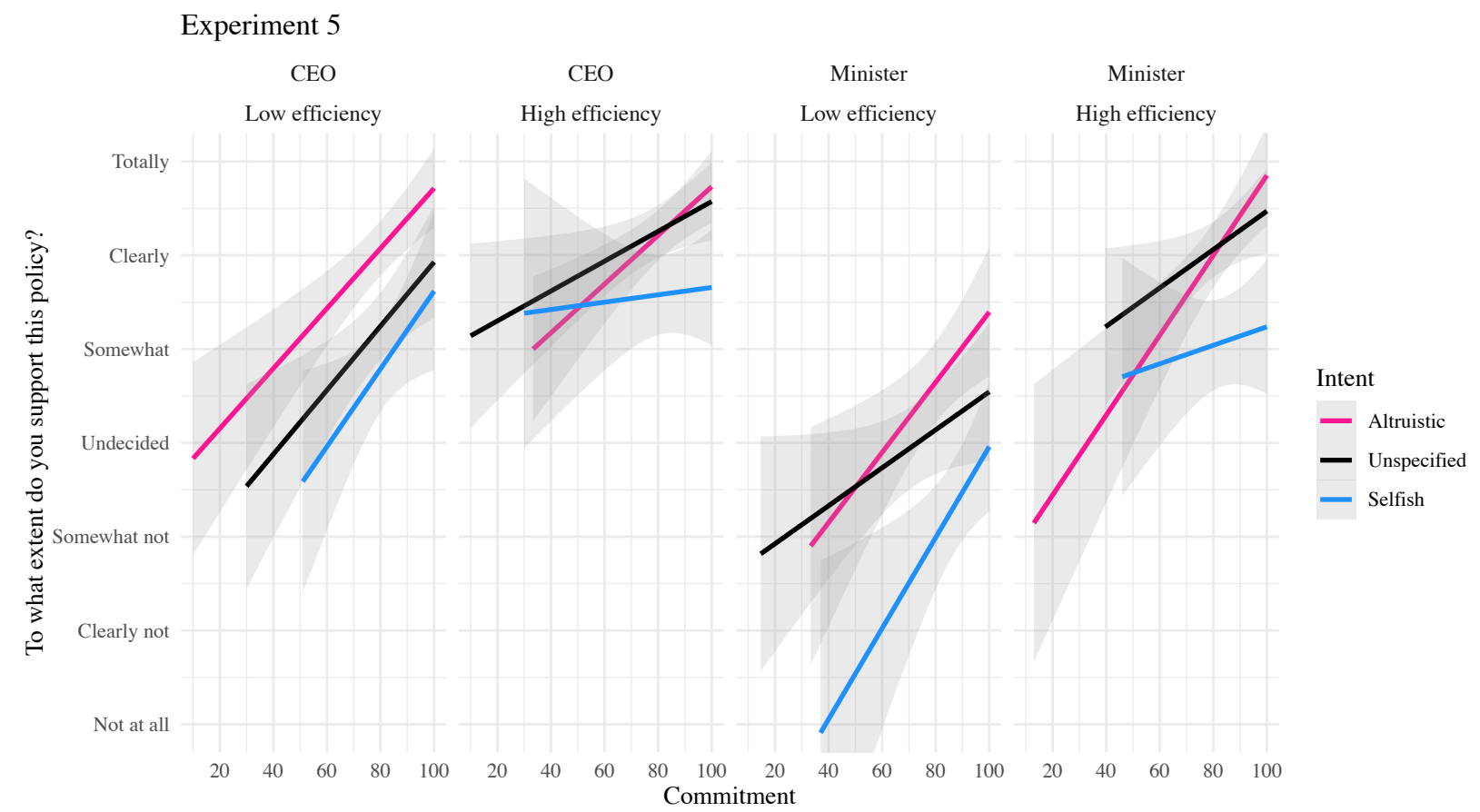

Figure 5: $\mathrm{N}=661$. Support for policy judgments in Experiment 2 as a function of moral commitment to the issue, intent and efficiency, breaking down by decision maker identity. Simple linear regressions with $95 \%$ CIs as greyed area.

Effect of moral commitment on judgments. Increased moral commitment to environmental protection systematically increased support for the policies, regardless of their efficiency (see Figures 3-5, bottom). The effect was first assessed using Experiment 2's main regression models (see "main models" in SM), in which the main effect of commitment was: $\beta=0.26,[0.20,0.33]$, $\mathrm{p}<0.001$. The effect of commitment on policy support was marginally smaller on high than low efficiency policies, presumably due to a ceiling effect on the policy support scale (interaction between commitment and high efficiency: $\beta=-0.12,[-0.25,0.01]$, but the interaction only approached significance: $p=0.07$ ). Consistent with Experiments 1, the positive effect of commitment on support for policy seemed greater when the decision maker was motivated by altruism than when no intention was specified, but the interaction was not significant 


\section{INTENTIONS VS. EFFICIENCY IN POLICY EVALUATIONS}

(interaction between commitment and altruistic intent: $ß=0.12,[-0.02,0.27], \mathrm{p}=0.10)$. The positive relationship between commitment and support for policy was not moderated by the decision maker being driven by selfishness compared to when no intention was specified (interaction between commitment and selfish intent: $ß=0.03,[-0.14,0.19], \mathrm{p}=0.75$ ).

\section{General Discussion}

Ministers and CEOs sit at the top of powerful organizational chains of command that allow them to make a potentially big difference on whatever societal and economic issue they decide to tackle. At the same tine, they are officials with whom most citizens will never have any personal relationship. By pragmatic standards - and contrary to relationships we have with friends and relatives with whom physical interdependence is higher - whether ministers and CEOs, as particular individuals, share our values or not should be of little import. What we should mostly care about is how successful policies are at reaching their goals, while balancing that against their cost for society.

Against moral pragmatism, our experiments $(\mathrm{N}=1515)$ found that laypeople's intuitive judgments of policy decisions were only little responsive to huge differences in efficiency expressed in numerical format. In Experiments $1(\mathrm{~N}=854)$, the fact that high efficiency policy decisions were at least 8 times more impactful than low efficiency policies, and that they would make society save rather than loose millions, never sufficed to make participants judge high efficiency decisions as more commendable than low efficiency ones. Experiment $2(\mathrm{~N}=661)$ showed that in the absence of any information on the decision maker's motivations, high efficiency policies at least 40 times more impactful than low efficiency policies (in addition to being hugely profitable rather than costly) received only 1.5 scale points more support than low efficiency policies $(\mathrm{d}=1.12)$.

Against pragmatic principles again, we also found that cues to the presence of altruistic vs. selfish intentions in policies' implementation have substantial influence on how commendable they are perceived (Exp. 1), and how much popular support they get (Exp. 2). When the policy's efficiency was low-i.e. when support for it was not already near the scale's maximum—adding information on the decision maker's altruistic intentions had a moderate increasing effect on 


\section{INTENTIONS VS. EFFICIENCY IN POLICY EVALUATIONS}

support compared to when no intention-relevant information was provided. Conversely,

portraying the policy as motivated by selfish reward—whether financial or electoral—decreased support for it compared to when information on intentions was absent, regardless of how efficient the policy was.

Expert discussions of policies' costs and benefits typically rely on figures which are then communicated by the media and appropriated by the public in informal conversations (Katz \& Lazarsfeld, 1955). Ordinary citizens should be able to take into account those figures if they are to form attitudes and vote in pragmatic ways. To the extent policy makers' decisions are influenced by their citizens' and employees' preferences, the combination of low responsiveness to efficiency and high sensitivity to intentions have the potential to lead to considerable missed opportunities and wasted money for society. They may bring citizens to support highly expensive political programs that achieve little so long as they pursue values they hold dear, and to overlook vastly efficacious and profitable ones just because the reason for their implementation is perceived as lacking nobility.

What is worse, people's capacity to engage in cost/benefit thinking on politics appears further lowered when they moralize the issue highly. Experiments 1 consistently showed that increased moral commitment to a societal value predicted greater support for well-intended but highly inefficacious and expensive policies aimed to promote the value. Experiment 2 suggested that greater moral commitment to an issue may increase support for any policy that somehow contributed to address the issue. The fact that moral commitment, in this latter study, had a positive effect on support for policy whether the policy sprung from altruism or selfishness is good news for the pragmatic. But the finding that the positive influence of commitment on policy support was not affected by efficiency is worrisome. It suggests that those who care the most about solving an issue may also be the ones most likely to relate deontologically to it - the ones least concerned to proportion efforts and resources to the targeted benefit (Skitka et al. 2005; Skitka 2010; Marie 2019, 2020).

An evolutionary approach to moral judgments can shed light on those results. Humans spent most of their evolution in small-scale societies in which the need to carry out joint ventures 


\section{INTENTIONS VS. EFFICIENCY IN POLICY EVALUATIONS}

would have required them to constantly gauge other individuals' trustworthiness as potential partners (Baumard, André, Sperber 2013; Tooby \& Cosmides 1990). As a result, they evolved intuitive inference systems for tracking cues diagnostic of a person's value as a cooperator, and moral character (Uhlmann, Pizarro, Diermeier, 2015).

Among other algorithms, a reliability-as-cooperator barometer would be expected to contain a simple heuristic tracking whether, in a given domain of cooperation (e.g. protecting the environment), an individual did, or did not, do their part (e.g. Yamagishi et al. 2007). In Experiment 2 for instance, what our participants mostly seemed to care about is whether the $\mathrm{CEO}$ or minister did something to reduce $\mathrm{CO}_{2}$ emissions rather than nothing, not how effective their program was in doing so. Use of a simple "Did they do their part?" heuristic, that outputs a "yes"/"no" dichotomous outcome, may contribute to explain this myopia to differences in policy efficiency. Moreover, the strong relationship between increased commitment and support for all versions of a policy, whatever its level of efficiency, suggests that the contribution of this simple heuristic to moral judgment may be proportional to a person's degree of moral commitment to the issue.

Note that people may have a myopic demand for cooperation in others while also expecting certain categories of actors to cooperate more than others. In Experiments 1, participants supported the same altruistic but low efficiency policy more if a CEO was implementing it than if it was a minister. In Experiment 2, low efficiency policies, regardless of the intentions driving them, garnered more support if they were implemented by a CEO than a minister. This may be due to French people having lower expectations towards private actors serving the common good than towards state servants (Rubin, 2014), and as a consequence, thinking that CEOs deserve more praise than ministers for identical, beneficial actions.

Moreover, among the cues an evolved reliability-as-cooperator barometer would be expected to attend in priority are the intentions of whomever might become one's cooperation partner. As a window into how a person orders her priorities, intentions provide crucial estimates of the future costs and benefits of personally collaborating with them, regardless of which particular situation one finds oneself in. Our brains are now thrown in a modern world in which a new and counter-intuitive moral standard has emerged - moral pragmatism-which requires them to turn down information to which they evolved to give instinctive importance: agents' 
trustworthiness as cooperators-e.g. CEOs' and ministers' trustworthiness as individualsinferred from their intentions. Instead, this counter-intuitive pragmatic standard requires them to focus on information they did not evolve to process: policies' abstract costs and benefits, expressed in multiple figures and percentages. Numerical notation is indeed a recent cultural innovation (Dehaene 2009), and quantities are notoriously easier to represent visually as lengths or areas than from numbers (Kirk 2016). Folk moral judgments of policies' propensity to depart from pragmatism may thus be explained in terms of a mismatch between our evolved psychology and the biologically novel demands of cost-benefit thinking.

\section{Authors' Contributions}

All authors contributed to the studies' design. A. Marie built the surveys, collected the data, performed the statistical analyses, reported the results and wrote the manuscript. H. Trad and B. Strickland provided revisions. All authors approved the final version of the manuscript for submission.

\section{Conflict of interest}

The authors declare having no conflict of interest.

\section{Acknowledgements}

The research leading to these results received funding from the European Research Council under the European Union's Seventh Framework Programme (FP/2007-2013) / ERC Grants 324115-FRONTSEM (PI: Schlenker) and 313610-SEMEXP (PI: Chemla), and ERC H2020 Grant Agreement No. 788077-Orisem (PI: Schlenker). Research was conducted at Institut d'Etudes Cognitives (ENS), which is supported by grants ANR-10-IDEX-0001-02 PSL*, ANR-10-LABX-0087 IEC, and ANR-17-EURE-0017 FrontCog.

\section{References}

Baron, J. (1994). Nonconsequentialist decisions. Behavioral and Brain Sciences, 17(1), 1-10. https://doi.org/10.1017/s0140525x0003301x 
INTENTIONS VS. EFFICIENCY IN POLICY EVALUATIONS

Baron, J., \& Spranca, M. (1997). Protected values. Organizational Behavior and Human Decision Processes, 70, 1-16.

Barrett, H. C., Bolyanatz, A., Crittenden, A. N., Fessler, D. M. T., Fitzpatrick, S., Gurven, M., Henrich, J., Kanovsky, M., Kushnick, G., Pisor, A., Scelza, B. A., Stich, S., von Rueden, C., Zhao, W., \& Laurence, S. (2016). Small-scale societies exhibit fundamental variation in the role of intentions in moral judgment. Proceedings of the National Academy of Sciences, 113(17), 4688-4693.

https://doi.org/10.1073/pnas.1522070113

Bentham, J. (1983). The collected works of Jeremy Bentham: Deontology, together with a table of the springs of action; and the article on utilitarianism. Oxford, UK: Oxford University Press. (Original work published 1879)

Berman, J. Z., Barasch, A., Levine, E. E., \& Small, D. A. (2018). Impediments to Effective Altruism: The Role of Subjective Preferences in Charitable Giving. Psychological Science, 29(5), 834-844. doi:10.1177/0956797617747648

Blancke, S., Van Breusegem, F., De Jaeger, G., Braeckman, J. \& Van Montagu, M. (2015). Fatal attraction: the intuitive appeal of GMO opposition. Trends in Plant Science. 20, 414-418. https://doi.org/10.1016/j.tplants.2015.03.011

Boyer, P. \& Petersen, M. B. (2018). Folk-economic beliefs: An evolutionary cognitive model. Behavioral and Brain Sciences, 41, e158. https://doi.org/10.1017/S0140525X17001960

Cameron, R., \& Taylor, M. (2011). The 2050 roadmap for nuclear: Making a global difference. Energy and Environment, 22(1-2), 1-15. https://doi.org/10.1260/0958-305X.22.1-2.1

Caviola, L., Schubert, S., Teperman, E., Moss, D., Greenberg, S., F., Nadira S. (2020). Donors vastly underestimate differences in charities' effectiveness. Judgment and Decision Making. 15(4), 509-516.

Dehaene, S. (2009). Reading in the Brain: The New Science of How We Read. Penguin. 
INTENTIONS VS. EFFICIENCY IN POLICY EVALUATIONS

Fernbach, P. M., Light, N., Scott, S. E., Inbar, Y., \& Rozin, P. (2019). Extreme opponents of genetically modified foods know the least but think they know the most. Nature Human Behaviour. doi:10.1038/s41562-018-0520-3

Fernbach, P.M. et al. (2013) Political extremism is supported by an illusion of understanding. Psychological Science. 24, 939-946. DOI: 10.1177/0956797612464058

Fiske, S. T., Cuddy, A. J. C., \& Glick, P. (2007). Universal dimensions of social cognition: warmth and competence. Trends in Cognitive Sciences, 11(2), 77-83. DOI:10.1016/j.tics.2006.11.005

Graham, J., \& Haidt, J. (2012). Sacred values and evil adversaries: A moral foundations approach. In M. Mikulincer \& P. R. Shaver (Eds.), Herzliya series on personality and social psychology. The social psychology of morality: Exploring the causes of good and evil (p. 11-31). American Psychological Association. https://doi.org/10.1037/13091001

Gray, K., Young, L., \& Waytz, A. (2012). Mind Perception Is the Essence of Morality. Psychological Inquiry, 23(2), 101-124. doi:10.1080/1047840X.2012.651387

Haidt, J. (2001). The emotional dog and its rational tail: A social intuitionist approach to moral judgment. Psychological Review, 108(4), 814-834. https://doi.org/10.1037/0033$295 \times .108 .4 .814$

Haidt, J. (2012). The Righteous Mind: Why Good People Are Divided by Politics and Religion: Vintage Books.

Henrich, J., Heine, S. J., \& Norenzayan, A. (2010). The weirdest people in the world? The Behavioral and Brain Sciences, 33,61-83; 83-135. doi:10.1017/S0140525X0999152X

Kant, I. 1785/2005. Groundwork for the metaphysics of morals (ed. L. Denis). Toronto, Canada: Broadview Press.

Katz, E., Lazarsfeld, P. F. (1955). Personal Influence. New York: Free Press. 
INTENTIONS VS. EFFICIENCY IN POLICY EVALUATIONS

Keil, F. C. (2003). Folkscience: coarse interpretations of a complex reality. Trends in Cognitive Sciences, 7(8), 368-373. doi:10.1016/S1364-6613(03)00158-X

Kirk, A. (2016). Data visualization. A Handbook for data driven design. London: Sage.

Marie, A. (2020). Moral rigidity evolved to strengthen bonds within groups. "What is extremism?" issue of This View of Life magazine, The evolution institute. Editors: Anthony C. Lopez, Hammad Sheikh, David Sloan Wilson. https://hisviewoflife.com/moral-rigidity-evolved-to-strengthen-bonds-within-groups/

Marie, A. (2019). Moral rigidity as a proximate facilitator of group cohesion and combativeness, commentary on De Dreu, C. K. W. \& Gross, J. (2019). Revisiting the form and function of conflict: Neurobiological, psychological, and cultural mechanisms for attack and defense within and between groups, p. 28, Behavioral and Brain Sciences, 42, e116: 1-66. DOI:10.1017/ S0140525X18002170

Marie, A., Altay, S., Strickland, B. (2020). Moral conviction predicts sharing preference for politically congruent headlines. OSF Preprint: 10.31219/osf.io/twq3y

Rozenblit, L., \& Keil, F. (2002). The misunderstood limits of folk science: an illusion of explanatory depth. Cognitive Science, 26(5), 521-562. doi:10.1207/s15516709cog2605_1

Rubin, P. H. (2003) Folk economics. Southern Economic Journal 70(1):157-71. doi: 10.2307/1061637.

Rubin, P. H. (2014). Emporiophobia (Fear of Markets): Cooperation or Competition? Southern Economic Journal, 80(4), 875-889. doi:10.4284/0038-4038-2013.287

Sidgwick, H. (1884). The methods of ethics (3rd ed.). London, England: Macmillan.

Siqueira, D. S., de Almeida Meystre, J., Hilário, M. Q., Rocha, D. H. D., Menon, G. J., \& da Silva, R. J. (2019). Current perspectives on nuclear energy as a global climate change mitigation option. Mitigation and Adaptation Strategies for Global Change, 24(5), 749-777. https://doi.org/10.1007/s11027-018-9829-5 
INTENTIONS VS. EFFICIENCY IN POLICY EVALUATIONS

Skitka, L. J. (2010). The Psychology of Moral Conviction. Social and Personality Psychology Compass, 4(4), 267-281. doi:10.1111/j.1751-9004.2010.00254.x

Skitka, L. J., Bauman, C. W., \& Sargis, E. G. (2005). Moral conviction: Another contributor to attitude strength or something more? Journal of Personality and Social Psychology, 88, 895-917. 10.1037/0022-3514.88.6.895

Slote, M. (1995). Agent-based virtue ethics. Midwest Studies in Philosophy, 20, 83-101. https://doi.org/10.1080/05568640409485132

Spranca, M., Minsk, E., \& Baron, J. (1991). Omission and commission in judgment and choice. Journal of Experimental Social Psychology, 27, 76-105. https://doi.org/10.1016/00221031(91)90011-T

Ståhl T., Zaal M.P., Skitka L.J. (2016). Moralized Rationality: Relying on Logic and Evidence in the Formation and Evaluation of Belief Can Be Seen as a Moral Issue. PLoS ONE 11(11): e0166332. doi:10.1371/journal.pone.0166332

Tooby, J., \& Cosmides, L. (1990). The past explains the present - Emotional adaptations and the structure of ancestral environments. Ethology and Sociobiology, 11, 375-424. https://doi.org/10.1016/0162-3095(90)90017-Z

Uhlmann, E.L., Pizarro, D. A. Diermeier, D. (2015) A person-centered approach to moral judgment. Perspectives on Psychological Science. 10(1) $72-81$.

DOI: $10.1177 / 1745691614556679$

Walmsley, J., \& O’Madagain, C. (2020). The Worst-Motive Fallacy: A Negativity Bias in Motive Attribution. Psychological Science, 31(11), 1430-1438. https://doi.org/10.1177/0956797620954492

Wesseler, J., \& Zilberman, D. (2014). The economic power of the Golden Rice opposition. Environment and Development Economics, 19(06), 724-742. doi:10.1017/S1355770X1300065X 
INTENTIONS VS. EFFICIENCY IN POLICY EVALUATIONS

Yamagishi T, Terai S, Kiyonari T, Mifune N, Kanazawa S (2007). The social exchange

heuristic: Managing errors in social exchange. Rationality and Society, 19(3), 259-291. https://doi.org/10.1177/1043463107080449

Young, L. \& Tsoi, L. (2013). When mental states matter, when they don't, and what that means for morality. Social and Personality Psychology Compass 7/8 (2013): 585-604, doi: $10.1111 /$ spc3.12044 
INTENTIONS VS. EFFICIENCY IN POLICY EVALUATIONS

\section{Supplementary Materials}

\section{Table of Contents}

Vignettes. .28

Experiment 1b: Pursuing sex equality in the workplace

Experiment 1c: Promoting France's diplomatic authority in the world 31

Experiment 1d: Regulating immigration 33

\section{Vignettes}

The following displays vignettes used in Experiments 2 to 4 . Paragraphs were separated by a line break in the original display. Translation was made from French using DeepL, and double checked for accuracy.

\section{Experiment 1b: Pursuing sex equality in the workplace}

\section{Altruistic intent/Low efficiency}

The CEO of a major communications agency is considering a new policy: to change the recruitment and compensation procedures for its employees in order to increase parity in the company and reduce the wage gap between men and women.

His advisor says: "By implementing this policy, you increase gender equality by $10 \%$. policy, you increase gender equality by $80 \%$.

\section{Selfish intent/High efficiency}

The CEO of a major communications agency is considering a new policy: to change the recruitment and compensation procedures for its employees in order to increase parity in the company and reduce the wage gap between men and women.

His advisor says: "By implementing this 
INTENTIONS VS. EFFICIENCY IN POLICY EVALUATIONS

But, despite the size of our company, the impact in terms of promoting parity would be minor, as it would only reduce gender inequality in the workplace by $0.001 \%$ worldwide. This policy could help only a little bit in the fight against gender inequality. »

The CEO said: "I honestly care deeply about fighting against gender pay inequalities and striving for parity. How much would the policy cost us?»

The advisor replied: "According to my calculations, our company would lose a total of about 100 million euros with this policy, because it would significantly increase production costs. »

The CEO decided to implement the policy. He effectively managed to reduce gender inequality in his company by $10 \%$, contributing to a minimal decrease of $0.001 \%$ in the international business world. But because he was personally very keen on this gesture, the $\mathrm{CEO}$ considered it well worth the 100 million euros in lost profits.
Given the size of our company, the impact in terms of promoting parity would be massive, as it would reduce gender inequality in the workplace by $1 \%$ globally. That's the kind of policy that could really help combat gender inequality. "

The CEO said: "Honestly, I really don't care about fighting gender pay inequalities and striving for parity. What I care about is the profits we can make and the success of our business. How much would the policy cost us? »

The advisor replied: "According to my calculations, our company would gain a total of around 100 million euros with this policy, as it would significantly reduce production costs. "

The CEO decided to implement the policy. He effectively reduced gender inequality in his company by $80 \%$, contributing to a significant decrease of $1 \%$ in the international business world. But more importantly for the CEO, he also made a profit of 100 million euros. 
INTENTIONS VS. EFFICIENCY IN POLICY EVALUATIONS 
INTENTIONS VS. EFFICIENCY IN POLICY EVALUATIONS

\section{Experiment 1c: Promoting France's diplomatic authority in the world}

\section{Altruistic intent/Low efficiency}

The Minister of Defense is considering a new policy: to restore France's authority and influence in the world by investing more in its diplomatic corps and military infrastructure.

His adviser told him: "By implementing this policy, you increase France's geopolitical influence by $10 \%$. But despite the size of our administration, the impact in terms of increased authority and influence abroad would be minor, as it would only reduce the problem of international political instability by $0.001 \%$. Such a policy could help only a tiny bit in advancing France's interests and values in the world. "

The Minister declared: "I honestly care deeply about restoring France's influence and authority internationally. How much would the policy cost us? "

The adviser replied: "According to my calculations, the State would lose about 100 million euros in total with this policy,

\section{Selfish intent/High efficiency}

The Minister of Defense is considering a new policy: to restore France's authority and influence in the world by investing more in its diplomatic corps and military infrastructure.

His adviser told him: "By implementing this policy, you increase France's geopolitical influence by $80 \%$. Given the size of our administration, the impact in terms of increased authority and influence abroad would be massive, as it would reduce the problem of international political instability by $1 \%$. This is the kind of policy that could really help advance France's interests and values in the world. »

The minister declared: "Honestly, I really don't care about restoring France's influence and authority internationally. What I care about is making budget savings that could increase the chances that our party will win the next election. How much would the policy cost us? »

The adviser replied: "According to my calculations, the State would save about 100 million euros in total with this policy, because it 
INTENTIONS VS. EFFICIENCY IN POLICY EVALUATIONS

because it would significantly increase the would significantly increase our bargaining wage bill. " power. "

The minister decided to implement the The minister decided to implement the policy. policy. He actually managed to increase He effectively increased France's influence and France's influence and authority abroad by authority abroad by $80 \%$, thus contributing to a $10 \%$, thus contributing to a $0.001 \%$ decrease $1 \%$ decline in political instability in the world. in political instability in the world. But More importantly for the minister, he also because he was personally very keen on this achieved a budget saving of 100 million euros, gesture, the minister considered it well worth which directly benefited his party. the 100 million euros lost by the state. 
INTENTIONS VS. EFFICIENCY IN POLICY EVALUATIONS

\section{Experiment 1d: Regulating immigration}

\section{Altruistic intent/Low efficiency}

The Minister of the Interior is considering a new policy: to make French migration policy more restrictive by making the granting of French nationality and the right of residence conditional on passing tests of knowledge of republican values (universalism and secularism), and of French culture, history and language.

His adviser told him: "By implementing this policy, you eliminate unwanted immigration and Islamism by $10 \%$. But, despite the size of our administration, the impact in terms of immigration regulation would be minor, as it would only reduce the problem of unwanted immigration and Islamism by $0.001 \%$ at the global level. This policy could only help a little bit in the fight against the influence of people refusing our values. »

The Minister said, "I honestly care deeply about restricting immigration rights to those who know and accept our values and culture. How much would the policy cost us? »

The adviser replied: "According to my calculations, the State would lose about 100

\section{Selfish intent/High efficiency}

The Minister of the Interior is considering a new policy: to make French migration policy more restrictive by making the granting of French nationality and the right of residence conditional on passing tests of knowledge of republican values (universalism and secularism), and of French culture, history and language.

His adviser told him: "By implementing this policy, you eliminate undesirable immigration and Islamism in France by $80 \%$. Given the size of our administration, the impact in terms of regulating immigration would be massive, as it would reduce the problem of unwanted immigration and Islamism by $1 \%$ globally. This is the kind of policy that could really help to fight the influence of people who refuse our values. »

The Minister said, "Honestly, I really don't care about restricting immigration rights to those who know and accept our values and culture. What I care about is making budget savings that could increase the chances of our party winning the next election. How much would the policy cost us? »

The adviser replied: "According to my calculations, the State would save about 100 million 
INTENTIONS VS. EFFICIENCY IN POLICY EVALUATIONS

million euros in total with this policy, because it would significantly increase the wage bill. »

The minister decided to implement the policy.

He effectively managed to reduce undesirable immigration and Islamism by $10 \%$, contributing to a minimal decrease of $0.001 \%$ in the world. However, because he was personally very keen on this gesture, the minister considered it well worth the 100 million euros lost by the state. euros in total with this policy, because it would significantly reduce the wage bill. »

The minister decided to implement the policy. He effectively reduced undesirable immigration and Islamism in France by $80 \%$, thus contributing to a significant decrease of $1 \%$ in the world. But more importantly for the minister, he also achieved a budget saving of 100 million euros which directly benefited his party. 